\title{
ARTICLE
}

\section{Study on evaluation of applying flocculating agents for efficient decontamination of radioactively contaminated soil}

\author{
Jong-Soon Song and Sun-Il Kim* \\ Chosun University, 309 Pilmun-Daero, Dong-Gu, Gwangju, 501-759, Republic of Korea
}

\begin{abstract}
The cases where the soil is widely contaminated by radioactive material include nuclear power plant accidents, such as Chernobyl and Fukushima, and repair of NPPs. The key nuclide involved in soil contamination is Cs, and Cs is emitted in gaseous form during an NPP accident and contaminates a wide area. The methods of recovering soil contaminated by radioactive materials include soil washing and electro-kinetic. In this paper, the authors selected the soil washing process, used flocculating agents, and measured the removal rate of the fine soil and Cs ions which are strongly combined with Cs. When the flocculating agent was put into the aqueous solution containing the fine soil and cesium, the maximum removal rate was $88 \%$, and the minimum removal rate was about $67 \%$.
\end{abstract}

\section{Keywords: Soil-washing; Visual MINTEQ; decontamination; cesium; flocculating agent}

\section{Introduction}

The representative cases in which radioactive materials are emitted in the soil are NPP accidents and maintenance of NPPs. The nuclides, which get the most interest in such cases, are Cs-137 and I-131, and these nuclides are emitted in gaseous form and causes contamination of a wide area. In particular, as the radioactive cesium ion $\left(\mathrm{Cs}^{+}\right)$emitted in the soil is strongly combined with clay and organic and inorganic materials, they are difficult to decontaminate. In this paper, the soil washing method was selected among soil decontamination methods. Flocculating agents were injected during the soil washing process, and the cesium strongly combined with the fine soil was removed for the purpose of reducing the soil decontamination time[1, 2].

\section{Soil decontamination methods and selections}

\subsection{Soil decontamination methods}

Soil decontamination methods are divided into physico-chemical methods, such as soil washing, soil vapor extraction and electro-kinetic, and biological methods, such as phytoremediation, bioventing and land-farming [3].

\subsection{Soil decontamination method selections}

\subsubsection{Application case of soil washing (Korea)}

The representative process, used to decontaminate soil contaminated with Cs is the soil washing method. This method was applied to decontamination of the soil TRIGA-Mark II\&III, the research reactors of the Korea Atomic Energy Research Institute as shown in Table 1 [4].

\subsubsection{Application case of soil washing (U.S.)}

Additionally, the international case was the decontamination of soil containing cesium-137 at the Oak Ridge National Lab. The US cases of soil washing are shown in Table 2 [5].

Table 1. Application case of soil washing (Korea).

\begin{tabular}{|c|c|}
\hline Soil Washing process $(0.05 \mathrm{mR} / \mathrm{h})$ & $\begin{array}{l}\text { Cs-137 } \\
\text { (Removal } \\
\text { rate) }\end{array}$ \\
\hline $\begin{array}{l}\text { Citric Acid } 0.05 \mathrm{M}, 3 \text { times repeated } \\
\text { decontamination }(0.063 \sim 1.0 \mathrm{~mm})\end{array}$ & $13.8 \%$ \\
\hline $\begin{array}{c}\text { Citric } 0.05 \mathrm{M}+\text { Ammonium sulfate } 0.2 \mathrm{M}, \\
3 \text { times repeated decontamination } \\
(0.063 \sim 1.0 \mathrm{~mm})\end{array}$ & $40.6 \%$ \\
\hline $\begin{array}{c}\text { Citric } 0.05 \mathrm{M}+\text { Ammonium Nitrate } 0.2 \mathrm{M} \text {, } \\
3 \text { times repeated decontamination } \\
(0.063 \sim 1.0 \mathrm{~mm})\end{array}$ & $38.8 \%$ \\
\hline $\begin{array}{c}\text { Citric } 0.05 \mathrm{M}+\text { Ammonium Potassium } \\
\text { Oxalate } 0.2 \mathrm{M} \text {, } \\
3 \text { times repeated decontamination } \\
(0.063 \sim 1.0 \mathrm{~mm})\end{array}$ & $3.1 \%$ \\
\hline
\end{tabular}

\footnotetext{
*Corresponding author. Email: kingdom17c@naver.com
} 
Table 2. Application case of soil washing (U.S.).

\begin{tabular}{|c|c|c|c|c|c|}
\hline Site & $\begin{array}{l}\text { Radio- } \\
\text { nuclide }\end{array}$ & \begin{tabular}{|c|} 
Pre- \\
Treatmen \\
t activity
\end{tabular} & \begin{tabular}{|c|} 
Post- \\
Treatment \\
activity
\end{tabular} & \begin{tabular}{|l} 
Amount of \\
Soil \\
Treatment
\end{tabular} & $\begin{array}{l}\text { Volume } \\
\text { Reduction }\end{array}$ \\
\hline \begin{tabular}{|c} 
Montclair- \\
West \\
Orange, New \\
Jersey, \\
1996 \\
\end{tabular} & $\begin{array}{c}\text { Ra-226 } \\
\text { U-235 } \\
\text { U-238 } \\
\text { Th-230 }\end{array}$ & $40 \mathrm{pCi} / \mathrm{g}$ & $11 \mathrm{pCi} / \mathrm{g}$ & $323,000 \mathrm{ya}^{\mathrm{z}}$ & $54 \%$ \\
\hline $\begin{array}{c}\text { Oak Ridge } \\
\text { National Lab. }\end{array}$ & Cs-137 & $\begin{array}{c}\text { Not } \\
\text { available }\end{array}$ & $\begin{array}{c}\text { Not } \\
\text { available }\end{array}$ & 25.5 tons & $70 \%$ \\
\hline $\begin{array}{c}\text { Brunei Site, } \\
\text { Texas }\end{array}$ & $\mathrm{U}, \mathrm{Ra}$ & $\begin{array}{c}70 \mathrm{ppm} \\
\text { (U) }\end{array}$ & $20.7(\mathrm{U})$ & 22,800 tons & $99 \%$ \\
\hline $\begin{array}{c}\text { Maywood, } \\
\text { Superfund } \\
\text { Site, New } \\
\text { Jersey }\end{array}$ & $\begin{array}{c}\text { Th-232 } \\
\text { Ra-226 } \\
\text { U-238 }\end{array}$ & \begin{tabular}{|c|}
$34 \mathrm{pCi} / \mathrm{g}$ \\
$(\mathrm{Th})$ \\
$8 \mathrm{pCi} / \mathrm{g}$ \\
$(\mathrm{Ra})$ \\
$7 \mathrm{pCi} / \mathrm{g}$ \\
$(\mathrm{U})$
\end{tabular} & $\begin{array}{c}1 \mathrm{pCi} / \mathrm{g} \\
(\mathrm{Th}) \\
1 \mathrm{pCi} / \mathrm{g} \\
(\mathrm{Ra}) \\
1 \mathrm{pCi} / \mathrm{g} \\
(\mathrm{U})\end{array}$ & 8,000 tons & $\begin{array}{c}\text { Not } \\
\text { Available }\end{array}$ \\
\hline \begin{tabular}{|c|} 
Newpark \\
Environment, \\
Texas \\
\end{tabular} & Ra-226 & $\begin{array}{c}100-700 \\
\mathrm{pCi} / \mathrm{g}\end{array}$ & $<5 \mathrm{pCi} / \mathrm{g}$ & $\begin{array}{l}2,700 \\
\text { drums }\end{array}$ & $95 \%$ \\
\hline
\end{tabular}

\section{Soil washing process and flocculating agent application experiment}

\subsection{Soil washing process}

If cesium is exposed and combined with the soil, it is combined with silt and clay, making it difficult to separate them. Accordingly, in this experiment, flocculating agents were injected into the fine soil in the Waste Water Equalization Tank for particle separation during the soil washing process in order to remove cesium. The soil washing process is illustrated in Figure 1.

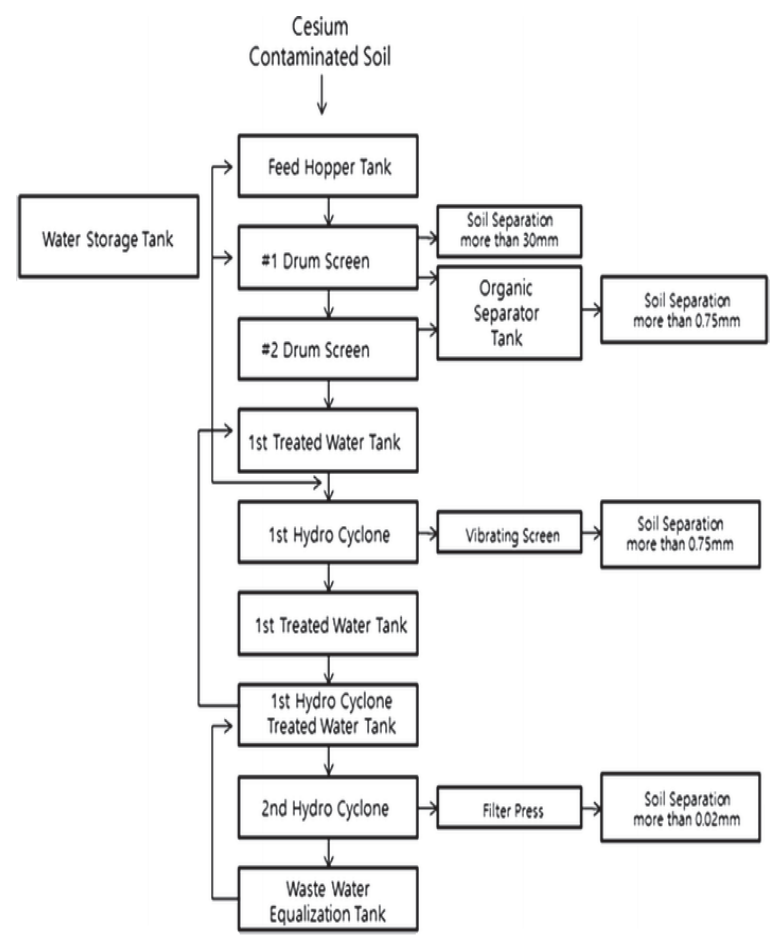

Figure 1. Soil washing process.

\subsection{Flocculating agent}

The Phyllite-based flocculating agent (J-AF) was selected for the cesium removal experiment. J-AF is a flocculating agent developed by Jeon Tech Co., Ltd. as part of the government project for wide-area soil decontamination. To examine the components of this flocculating agent, MSDS (Material Safety Data Sheets) analysis was conducted, and the components are listed in Table 3.

Table 3. Components of J-AF.

\begin{tabular}{|c|c|c|c|c|}
\hline $\mathrm{Al}_{2} \mathrm{O}_{3}$ & $\mathrm{SiO}_{2}$ & $\mathrm{Fe}_{2} \mathrm{O}_{3}$ & $\mathrm{CaO}$ & $\mathrm{MgO}$ \\
\hline 21.74 & 0.12 & 18.75 & 18.01 & 8.13 \\
\hline $\mathrm{K}_{2} \mathrm{O}$ & $\mathrm{Na}_{2} \mathrm{O}$ & $\mathrm{SO}_{3}$ & $\mathrm{Cl}$ & $\mathrm{OH}$ \\
\hline 2.12 & 11.62 & 6.29 & 0.13 & 13.08 \\
\hline
\end{tabular}

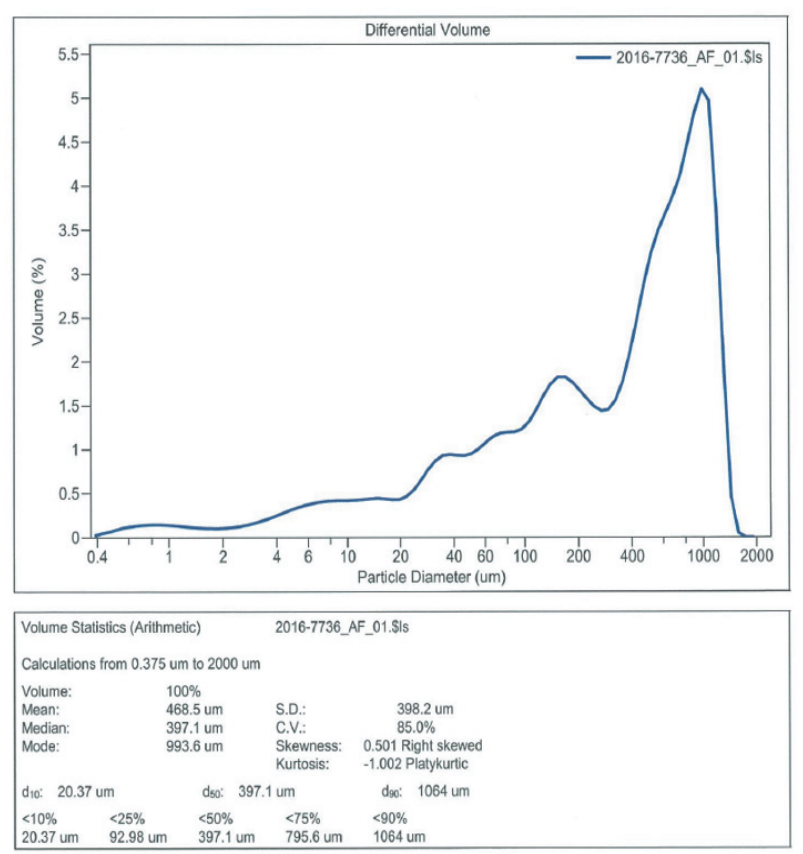

Figure 2. Particle size analysis of flocculating agent (J-AF).

\subsection{Flocculating agent application experiment}

Before the experiment, soil was collected from the site of Chosun University, and was separated with a $38 \mu \mathrm{m}$ sift. The sifted soil was dried for 20 minutes in a vacuum dryer. The $1 \mathrm{~g}$ of dried soil was put in the $100 \mathrm{~mL}$ of $10 \mathrm{mmol} / \mathrm{L}$ cesium solution made of $\mathrm{CsNO}_{3}(99 \%$, Sigma-Aldrich, USA). It was mixed for 24 hours under the conditions of $\mathrm{pH} 6.5,25^{\circ} \mathrm{C}$ and $250 \mathrm{rpm}$.

In the first experiment, after the injection of the flocculating agent (J-AF), the degree to which the fine soil, combined with cesium, was removed over time was analyzed. $0.1 \mathrm{~g}$ of the flocculating agent was injected into the conical tubes, containing $50 \mathrm{~mL}$ of simulated cesium aqueous solution, with the initial concentration being 0.1 , $1,2,5$ and $10 \mathrm{mmol} / \mathrm{L}$. The supernatant of the aqueous solution was extracted using the $0.2 \mu \mathrm{m}$ (Cellulose Nitrate Membrane Filter) filter. The extracted supernatant was used to analyze the concentration of the 
residual cesium by means of ICP-OES (Optima 2100DV, PerkinElmer Co., USA). The cesium removal rate of the flocculating agent over time is shown in Figure 2.

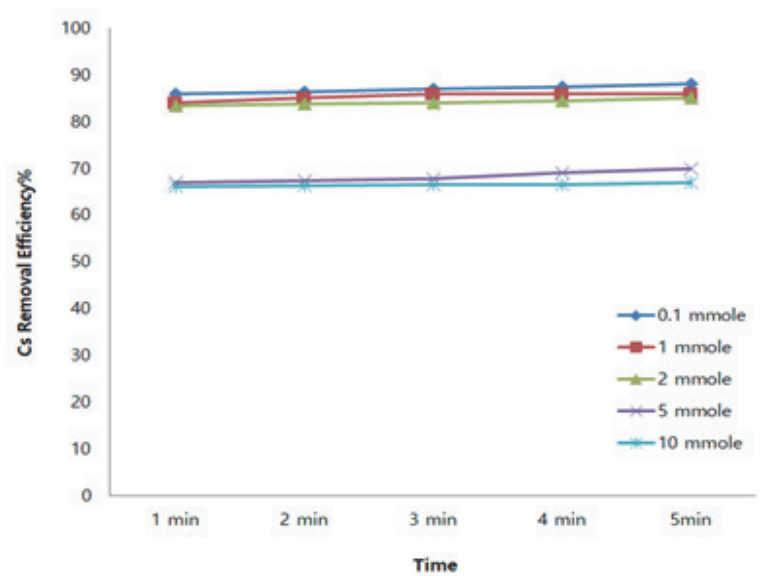

Figure 3. Flocculating agent removal rate performance over time.

In the second experiment, the cesium removal rate of the flocculating agent by cesium concentration was measured. The experiment was conducted in the same conditions as the first experiment, and the supernatant was extracted every minute a total of 5 times using the $0.2 \mu \mathrm{m}$ (Cellulose Nitrate Membrane Filter) filter, and the concentration of the residual cesium was measured with ICP-OES. The removal rate by cesium concentration is shown in Figure 3.

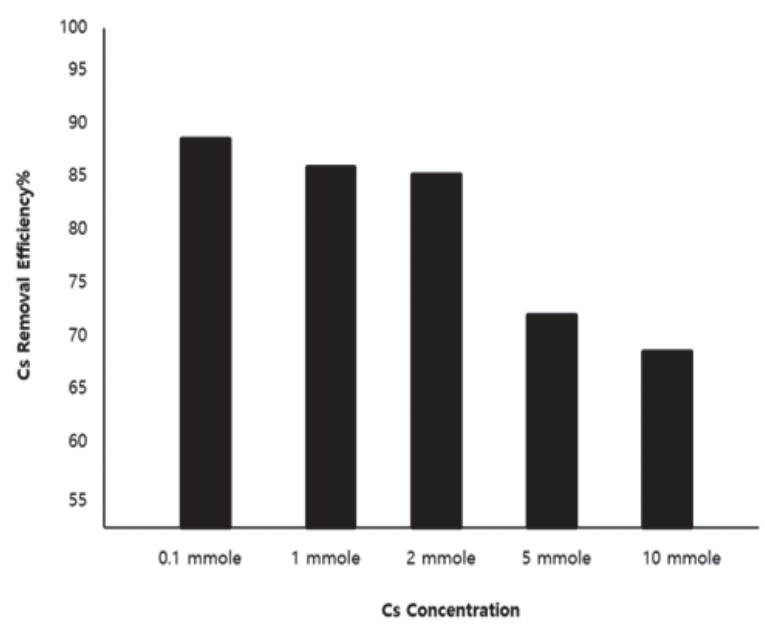

Figure 4. Flocculating agent removal rate performance for each Cs concentration.

\subsection{Prediction of species bond by Visual MINTEQ}

In this experiment, the flocculating agent was injected into the wash water during the soil washing process, and the fine soil, combined with cesium, was sedimented to reduce the decontamination and improve the efficiency of decontamination. The Visual MINITEQ Code, an adsorption isotherm code, was used to predict the degree of combination between the fine soil and Cs. Also, the degree to which the flocculating agent sedimented the fine soil in the wash water was analyzed through measurement of turbidity.

The Visual MINTEQ Code is made using the MINTEQA2 software of U.S.EPA, and makes it possible to calculate equilibrium, sorption and adsorption in the aqueous solution. The components of the soil, collected from the school site, were applied to the Visual MINTEQ Code [6]. As the authors failed to obtain the component analysis data of the soil from Chosun University, however, the cation and anion CEC (Cation Exchange Capacity) of the soil, collected from the date farm in Boeun, Chungcheongbuk-do, were converted into ppm, and applied, and the cation and anion concentration of the soil is shown in Table 4 [7]. The temperature as $25^{\circ} \mathrm{C}, \mathrm{pH}$ was 6.5 , the concentration unit was $\mathrm{mg} / \mathrm{kg}$, and the L/S ratio was 0.01 , and the default values of the Code were used for the remaining values. Table 5 shows the result values of the Code. $\mathrm{Cs}+1$ ion was applied to the Code by concentration, i.e. 0.1, 1, 2, 5 and $10 \mathrm{mmol}$, and species bond, i.e. the degree to which it is combined with the components of the soil, was predicted. It can be said that \% of the $\mathrm{Cs}+1$ ion in the species name is not combined with the components of the soil, and the $\mathrm{Cs}+$ ion remains as is $[8,9]$.

Table 4. Soil CEC of Gochang-gun, Jeollabuk-do.

\begin{tabular}{|c|c|c|c|}
\hline \multicolumn{4}{|c|}{ Soluble Cation and Anion $(\mathrm{Cmolc} / \mathrm{kg})$} \\
\hline $\mathrm{K}$ & $\mathrm{Ca}$ & $\mathrm{Mg}$ \\
\hline 0.3 & \multicolumn{2}{|c|}{2.4} & 1.2 \\
\hline \multicolumn{4}{|c|}{ Concentration of Anion $(\mathrm{mg} / \mathrm{kg})$} \\
\hline $\mathrm{Cl}$ & $\mathrm{N}_{3}$ & $\mathrm{PO}_{4}$ & $\mathrm{SO}_{4}$ \\
\hline 536 & 374 & 18.4 & 1,068 \\
\hline
\end{tabular}

Table 5. Cs and Soil Species combination predict of by Visual MINTEQ.

\begin{tabular}{|c|c|c|}
\hline Component & $\begin{array}{c}\% \text { of total } \\
\text { Concentration }\end{array}$ & Species name \\
\hline \multirow{4}{*}{$\begin{array}{c}\mathrm{Cs}+1 \\
(0.1 \mathrm{mmol})\end{array}$} & 8.433 & $\mathrm{Cs}+1$ \\
\hline & 47.877 & $\mathrm{CsCl}$ \\
\hline & 15.417 & $\mathrm{CsSO}_{4}$ \\
\hline & 28.272 & $\mathrm{CsNO}_{3}$ \\
\hline \multirow{4}{*}{$\begin{array}{c}\mathrm{Cs}+1 \\
(1 \mathrm{mmol})\end{array}$} & 8.605 & $\mathrm{Cs}+1$ \\
\hline & 47.946 & $\mathrm{CsCl}$ \\
\hline & 15.230 & $\mathrm{CsSO}_{4}$ \\
\hline & 28.219 & $\mathrm{CsNO}_{3}$ \\
\hline \multirow{4}{*}{$\begin{array}{c}\mathrm{Cs}+1 \\
(2 \mathrm{mmol})\end{array}$} & 8.801 & $\mathrm{Cs}+1$ \\
\hline & 48.014 & $\mathrm{CsCl}$ \\
\hline & 15.028 & $\mathrm{Cs} 5 \mathrm{O}$ \\
\hline & 28.157 & $\mathrm{CsNO}_{3}$ \\
\hline \multirow{4}{*}{$\begin{array}{c}\mathrm{Cs}+1 \\
(5 \mathrm{mmol})\end{array}$} & 9.431 & $\mathrm{Cs}+1$ \\
\hline & 48.172 & $\mathrm{CsCl}$ \\
\hline & 14.455 & $\mathrm{CssO}_{4}$ \\
\hline & 27.943 & $\mathrm{CsNO}_{3}$ \\
\hline \multirow{4}{*}{$\begin{array}{c}\mathrm{Cs}+1 \\
(10 \mathrm{mmol})\end{array}$} & 10.633 & $\mathrm{Cs}+1$ \\
\hline & 48.271 & $\mathrm{CsCl}$ \\
\hline & 13.595 & $\mathrm{CsSO}_{4}$ \\
\hline & 27.502 & $\mathrm{CsNO}_{2}$ \\
\hline
\end{tabular}




\subsection{Measurement of turbidity}

Turbidity was measured before and after the flocculating agent was injected into the aqueous solution in which the soil and Cs were mixed to check (1) flocculating agent whether the wash water could be reused, (2) how much fine soil was removed from the aqueous solution, and (3) how much soil was removed by the flocculating agent. Turbidity, as measured by a LaMotte 2020 turbidity meter, was recorded to be 47.2 NTU (Nepthelometric Turbidity Units) before the flocculating agent was administered, and it was found that the wash water became clear at 4.39 NTU after the flocculating agent was administered [10].

\subsection{Result of assessment}

In the experiment, ICP-OPS was used to measure the removal rate when $0.1 \mathrm{~g}$ of flocculating agent was applied. It was found that when the concentration of $\mathrm{Cs}$ is $0.1 \mathrm{mmol}$, the maximum Cs removal rate is about $88 \%$, when it is $1 \mathrm{mmol}$, it is $85.8 \%$, when it is $2 \mathrm{mmol}$, it is about $85 \%$, when it is $5 \mathrm{mmol}$, it is about $71 \%$, and when it is $10 \mathrm{mmol}$, it is about $67 \%$.

Also, if the turbidity values before and after injections of flocculating agent are compared, turbidity is 4.39 NTU after the injection. This is below the 10-NTU approved for domestic water quality criterion for reuse as industrial water. Additionally, $\mathrm{pH}$ is $5.8 \sim 8.5$ and BOD (Biochemical Oxygen Demand) is $6 \mathrm{mg} / \mathrm{L}$ or less. When turbidity and $\mathrm{pH}$ are taken into consideration, it is believed that the wash water can be reused [10].

$\mathrm{Cs}$ and soil are mixed in the Cs removal experiment to create an environment similar to a situation in which $\mathrm{Cs}$ and soil are combined in the natural environment. Accordingly, the prediction of the combination between soil and Cs using Visual MINTEQ indicates how much Cs and soil are combined and adsorbed.

Turbidity measurements indicate how much the flocculating agent can remove soil adsorbed with Cs from the mock Cs waste. To compare actual measurements and predicted values, the value obtained by multiplying the value of species bond predicted using Visual MINTEQ according to turbidity, and the actual ICP-OES measurements were compared. The graph comparing the actual measurements and predicted values is shown in Figure 4.

The graph comparing the actual measurements and predicted values show that the values are similar in the $0.1 \sim 2 \mathrm{mmol}$ area, but if the concentration becomes $2 \mathrm{mmol}$ or higher, it was confirmed that the difference between the two values was obvious. If more time is given for mixing soil and Cs than in this experiment, it is believed that the differences in the graph can be reduced. Also, if the CEC of the soil of nuclear power plants and related facilities using nuclear power is measured, and the species bond predicted, it is believed that the efficiency of the soil washing process can be predicted.

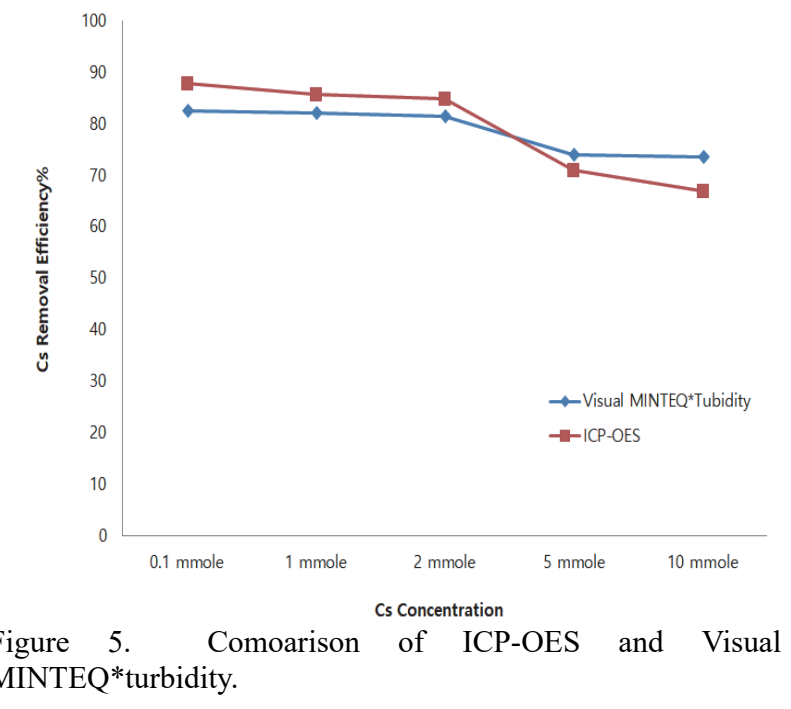

\section{Conclusion}

To The most suitable method of removing radionuclides from soil contaminated as a result of unexpected accidents during dismantling and maintenance of nuclear power plants is the soil washing method, which is commonly used domestically as well as internationally. The soil washing process takes less time than other processes but offers relatively high decontamination efficiency. The most important factors of the soil washing process are the particle separation of the soil, wash water selection, and the application of the adsorbent and flocculating agent to improve efficiency. In consideration of this, if a small area is contaminated with radioactive materials, simultaneous soil decontamination is not necessary. So the soil washing process, which has high decontamination efficiency as it applies the acid wash water and selective adsorbent, is appropriate. If a wide area is contaminated with radioactive materials, however, decontamination activities must be carried out simultaneously in a short period time. For these reasons, the soil washing process, which uses water together with flocculating agent injected into the soil in order to render the wash water reusable and improve the Cs removal rate, is more suitable. Also, as the flocculating agent, which was applied to the experiment for this study, takes very little time to form flocs it can further reduce the soil washing time. It is believed that this method can be used to more quickly process soil contaminated by radioactive materials as a result of a nuclear power plant accident or decommissioning.

The concentration of soil contamination due to nuclear power plant accidents and leakage of radioactive materials is very low being at the level of $\mathrm{ppb}$. Accordingly, the authors are planning to supplement the experiment conducted for this study by conducting a low-concentration experiment at the ppb level. Also, as a follow-up, the authors will analyze the flocculating agent mechanism of the flocculating agent to improve the overall efficiency of the soil washing process. 


\section{Acknowledgements}

This work was supported by the Korea Institute of Energy Technology Evaluation and Planning (KETEP) and the Ministry of Trade, Industry \& Energy (MOTIE) of the Republic of Korea (No. 20164030201290, 20141510300310).

\section{References}

[1] J.S. Song and S.I. Kim, A study on the assessment of treatment technologies for efficient remediation of radioactively-contaminated soil, JNFCWT, Vol.14(3) (2016), pp.245-251.

[2] W.S Kim, S.S Kim, G.N Kim, U.R Park and J.K Moon, Improved treatment technique for the reuse of waste solution generated from a electrokinetic decontamination system, Journal of Nuclear Fuel Cycle and Waste Technology 12 (1) (2014), pp.1-6.

[3] G.N. Kim, W.K. Choi, C.H. Jung and J.K. Moon, Development of a washing system for soil contaminated with radionuclides around TRIGA reactors, JKSIEC, 1(3) (2007), pp.406-413.

[4] W.J. Oh, H.J. Won, C.H. Jung, W.K. Choi, G.N. Kim and G.W. Lee, Decontamination technology development for nuclear research facilities, KAERI
Technical Report, RR-2416 (2003).

[5] Technology Reference Guide for Radioactively Contaminated Media, U.S.EPA, EPA 402-R-07-004 (2007).

[6] J.P Gustafsson, Visual MINTEQ Ver3.1 Manual, Royal Institute of Technology, Sweden (2000).

[7] B.Y. Jung, K.S. Lee, M.G. Kim, Y.H. Choi, M.K. Kim and J.Y. Cho Physico-chemical properties of rainfall interception culture and open field culture soil of of rubus sp. in Gochang-gun, Jeollabuk-do, Korean J. Soil Sci. Fert, 41(5) (2008), pp.303-309.

[8] J.S Yoon, Absorption characteristics of heavy metals in soils and their removal efficiency of soil washing technique using EDTA and NTA, Thesis of Master's Degree, Seoul National University (1999).

[9] H.S Lee, Y.H Choi, H.J Choi and H.S Kang Development of periodic safety review technology for nuclear power plant, KAERI, KAERI/RR-2245/ 2011 (2001).

[10]K.H Park, Based on guidelines for water reuse facility design and maintenance, Korea Water and Wastewater Works Association, Ministry of Environment, GSDS Press, Seoul (2007). 